\title{
Vivienda sin ciudad, ciudad sin planificación, planificación sin habitantes: APP para la reconstrucción territorial post-desastre $^{1}$
}

\author{
Housing without city, city without planning, planning \\ without inhabitants: PPP for urban post-disaster \\ reconstruction
}

\author{
Xenia Fuster-Farfán ${ }^{2}$ (D), Paulina Vergara Saavedra ${ }^{3}$ (1) \\ y Walter Imilán ${ }^{4}$ (1)
}

\begin{abstract}
RESUMEN
Los desastres socionaturales y sus procesos de reconstrucción son una oportunidad para los territorios y sus comunidades. Posterior al terremoto y tsunami del 27 de febrero del 2010, en Chile se creó un modelo de alianzas público-privadas (APP) a través de la formulación de Planes Maestros. Estos instrumentos tenían la misión de orientar el ordenamiento y reconstrucción territorial post-desastre en las localidades más afectadas. El "PRES Constitución" fue el Plan Maestro más publicitado de todos. La noción de APP para la reconstrucción territorial requiere de una mayor atención conceptual para analizar su propuesta de innovación basada en la participación ciudadana y acción de equipos técnicos de alto nivel. El principal proyecto habitacional de la ciudad, Villa Verde, expone a 10 años de la catástrofe, las limitaciones de este modelo para quebrar las tendencias de las prácticas de planificación implementadas en las últimas décadas en Chile. El artículo se interroga ¿en qué medida el modelo PRES logra revertir el camino trazado por la planificación en Chile que ha contribuido a las desigualdades territoriales? Particularmente, respecto a la relación entre privados y Estado y de la capacidad de involucrar a los y las habitantes en el proceso de reconstrucción, dos dimensiones fuertemente celebradas durante la implementación del PRES . La evidencia muestra que la racionalidad tecnocrática e interés privado propias de las APP, reprodujeron antiguas prácticas de planificación territorial. El texto se basa en una experiencia sistemática de trabajo con comunidades de la ciudad de Constitución entre los años 2010 y 2018.
\end{abstract}

Palabras clave: reconstrucción territorial, Planes Maestros, alianzas público-privadas, participación ciudadana

Este trabajo fue financiado por ANID - Programa Iniciativa Científica Milenio - Núcleo Milenio Movilidades y Territorios -MOVYT, NCS17_027 , y la Subdirección de Capital Humano/Becas Chile/2016-72170352. 


\begin{abstract}
Socio-natural disasters and their reconstruction processes are an opportunity for the territories and their communities. The $27 \mathrm{~F}$ disaster initiated a Private Public Partnership (PPP) model that gave birth to the formulation of Master Plans as instruments of territorial planning and reconstruction. The PRES Constitution was the most publicized Master Plan of all. PPP for urban reconstruction claims for more conceptual attention to grasp its purpose of innovation and high-quality solutions based on citizen participation and high-level technical teams. The main housing project in Constitución, Villa Verde, exposes the limitations of this model in order to break the trends in planning practices implemented in recent decades in Chile. The paper seeks to ask to what extent the PRES model overcomes the deficiencies of regular urban policies? And, to what extent were the affected communities involved? The findings show a reproduction of past planning practices due to technocratic rationality and private interests. The paper is based on a systematic experience of fieldwork since 2010 with the communities of Constitución.
\end{abstract}

Key words: Urban Reconstruction, Master Plan, Private-public Partnerships, citizen participation

Los desastres socionaturales y sus procesos de reconstrucción son una oportunidad para los territorios y sus comunidades, y de forma especial, una oportunidad para repensar y rediseñar políticas y prácticas de planificación (Archer \& Boonyabancha, 2011). En Chile y América Latina el vínculo entre desastres y ordenamiento territorial ha sido recurrente (Arenas et al., 2010; Hardoy et al., 2011; Rivera \& Wamsler, 2014). Nuevas políticas y programas no sólo se movilizan como una oportunidad para hacer frente a la reconstrucción de asentamientos, sino como estrategias de desarrollo territorial, mejorar la calidad de vida urbana y rural, rehabilitar áreas deterioradas y preparar al territorio y a sus habitantes de cara a un nuevo evento catastrófico (Godschalk, 2003; Pelling, 2003; Guo, 2012). En Chile, los procesos de reconstrucción territorial a lo largo del siglo $\mathrm{XX}$ dieron nacimiento a nuevas instituciones, normativas y regulaciones que desplegaron procesos de desarrollo económico y prácticas constructivas con mayor seguridad para los habitantes (Lawner, 2011). El proceso que siguió al terremoto y tsunami del 27 de febrero de $2010^{5}$ no fue ajeno a este espíritu de transformación de prácticas de planificación territorial.

El terremoto y tsunami del $27 \mathrm{~F}$ impactó a seis regiones del país, afectando a cerca del $80 \%$ de la población nacional. El gobierno desplegó un plan de reconstrucción centrado en la reparación y reposición de viviendas y de reconstrucción territorial a través de Planes Maestros. En el ámbito de vivienda se utilizó principalmente programas habitacionales regulares con modificaciones administrativas, mientras que para la reconstrucción territorial se propuso introducir el Plan Maestro como herramienta directriz. Investigaciones recientes han analizado el impacto de la introducción masiva de este instrumento. Algunas centradas en analizar, y en cierta forma celebrar, la aparente innovación en el ámbito de la gobernanza urbana (Tironi, 2014; Farías, 2016; Farías \& Flores, 2017). Otras con una mirada crítica, identifica estos procesos como parte de la profundización de lógicas neoliberales en las prácticas de planificación y en la exacerbación de las desigualdades territoriales (Imilan \& González, 2017; Fuster \& Larenas, 2018; Letelier \& Irazábal, 2018).

En el 2010, la elaboración de un Plan Maestro para la reconstrucción de ciudades pequeñas e intermedias resultaba algo inédito. Hasta ese momento esta herramienta sólo se había emplea- 
do de forma circunstancial. En el contexto de reconstrucción, el Plan Maestro se plantea como un instrumento indicativo y no normativo. Así, los instrumentos de ordenamiento territorial que zonifican (Planes Reguladores Comunales e Intercomunales) se mantienen durante el período post-desastre en su exclusividad normativa. E I Plan Maestro buscaba construir una imagen armónica e integrada de la ciudad, coordinando los diferentes proyectos de reconstrucción de infraestructura, de servicios y habitacionales que se desarrollaron posterior a la catástrofe. Con este fin se elaboraron 133 planes a lo largo de todo el país ${ }^{6}$.

El modelo promovido por los Planes Maestros tuvo al menos dos características. Primero, para su formulación fue convocada la participación activa del sector privado; promovida a través de alianzas público-privadas en diferentes escalas (financiamiento, gestión, implementación). Segundo, estos planes pusieron el acento en la construcción de proyectos habitacionales, urbanos y de viabilidad. Su acción se basa en la habilitación de suelo para el desarrollo de infraestructura y equipamiento, y la definición de una cartera de proyectos. . La planificación urbana a través de proyectos es una estrategia de gran impacto simbólico que se utiliza con el fin de estimular el desarrollo económico, organizar la innovación y flexibilizar procesos (Swyngedouw et al., 2002). El resultado en Chile de este modelo ha implicado desdeñar las formas de habitar y necesidades específicas de las comunidades, produciendo ciudades fragmentadas social, espacial y temporalmente (De Mattos, 2002; Borsdorf, 2003; Jirón \& Mansilla, 2014).

La ciudad de Constitución devino en un ejemplo con alta exposición pública del modelo antes descrito. El Plan Maestro de Reconstrucción Estratégico Sustentable de Constitución (PRES Constitución) fue un instrumento concebido a partir de una alianza público-privada (APP) con un conjunto de actores privados, liderado por el conglomerado Celco-Arauco ${ }^{7}$, importante actor económico en la ciudad y de la industria forestal nacional e internacional ${ }^{8}$. El PRES formuló una cartera de proyectos de recuperación de infraestructura urbana y de servicios, junto a ellos, la construcción de "Villa Verde"; el principal proyecto habitacional post-desastre en Constitución. El interés que reviste este caso no es sólo que ha logrado notoriedad pública debido a la contratación de la mediática oficina de arquitectura Elemental S.A, sino que fue promocionada como una nueva forma de APP, no explorada en las prácticas de planificación territorial hasta entonces.

En el presente texto analizamos el caso de Villa Verde a cinco años de su habitación. Los resultados aquí expuestos se basan en el estrecho y regular trabajo con la comunidad de Constitución iniciado el año 2011, en que nos comprometimos como equipo de profesionales y académicos para apoyar el proceso de reconstrucción de las comunidades. Desde esa posición, construimos relaciones con la comunidad que permitieron acompañar y observar críticamente los procesos que involucraron a sus habitantes. Transcurridos cinco años de la entrega del proyecto nos permite discutir las repercusiones de este modelo de planificación territorial en su existencia concreta. Nos preguntamos ien qué medida los Planes Maestros representan una forma de construir un camino diferente al trazado por las prácticas de planificación en Chile, las que han producido históricamente desigualdades territoriales? En virtud de ello, ponemos el foco en dos dimensiones

Para ver una descripción detallada de la implementación de estos planes se sugiere revisar Irazábal (2015) A lo largo del texto se hará alusión a Celco o Arauco para hacer referencia al conglomerado Celco-Arauco.

A este conglomerado están asociadas mineras, inmobiliarias, empresas de gas y combustible, eléctricas, pesqueras, entre otras vinculadas al consorcio empresarial chileno "Grupo Angelini" 
específicas: su cualidad innovadora como instrumento de gestión en la relación entre privados y Estado; y su capacidad de involucrar participativamente a los y las habitantes. La hipótesis de este trabajo plantea que, si bien la modalidad de APP implica un nuevo rol de los privados dentro de la planificación territorial, se trata de la incorporación de nuevos elementos que profundizan y no modifican los efectos negativos de las políticas urbano-habitacionales en Chile. Junto con ello, se reproducen lógicas que no reconocen a las comunidades como actores en la producción del territorio, fortaleciendo la individualización para el mejoramiento de las condiciones del habitar.

La planificación y formas de producción del espacio en Chile han sido definidas ampliamente como neoliberales (Hidalgo \& Janoschka, 2014); las alianzas público-privadas APP se encuentran en el corazón de este modelo. En este sentido, si bien es cierto la cooperación entre el ámbito público y el privado es de larga data en Chile (Hidalgo, 2019), el concepto de APP surge luego de la Cumbre de Río de 1992, en que organismos internacionales insistieron en la urgencia de un rol más activo por parte del sector privado para promover la Agenda 21 de desarrollo (Faulkner, 1997 citado en Casado, 2005). Las APP han sido promovidas como acuerdos entre sectores donde parte de las responsabilidades y riesgos del sector público se comparten con el privado, en concordancia con el principio de subsidiariedad. En este sentido, Ong (2011) y Hackworth (2007) coinciden en definir que la característica central de lo neoliberal no es una determinada forma de Estado, sino las relaciones entre lo público y privado, es decir, la búsqueda de alianzas patrocinadas por el Estado beneficiosas para el interés privado en diferentes campos de la vida social. Así, las APP en el contexto neoliberal expanden el campo de la cooperación público-privada; se trata de transferir subsidiariamente al privado las responsabilidades que, en el período desarrollista latinoamericano, eran de responsabilidad del Estado, como es el caso de la planificación territorial.

El texto se organiza con una sección de metodología donde se explicita el proceso de nuestra investigación y posicionalidad en ella. A continuación se presenta una síntesis de los debates en torno a la planificación neoliberal en Chile, y la importancia de las APP en este contexto. La sección cuatro presenta el PRES Constitución como una nueva estrategia de APP en el contexto de la planificación territorial, a modo de comprender el verdadero "experimento" del proceso de reconstrucción post 27F. Este proceso supuso la construcción de una nueva relación entre los privados, el Estado y la comunidad afectada de Constitución. Junto a la información producida durante años de trabajo en la ciudad, en la última sección presentamos específicamente el caso de Villa Verde para responder las preguntas que nos hemos planteado en este artículo con una mirada a 10 años del inicio de la implementación del PRES.

\section{Metodología y posicionalidad}

Los resultados y análisis de este artículo se enmarcan en un proceso que se inició el año 2010', realizando un seguimiento del proceso post-desastre y apoyando a comunidades en talleres de lide-

\footnotetext{
A finales del año 2010 creamos el proyecto "Observatorio de la Reconstrucción" como una iniciativa triestamental de la Universidad de Chile. Se logró el financiamiento de tres proyectos por el Fondo Valentín Letelier (2010-2011, 2012-2013, 2015-2016), junto con recibir apoyo financiero para realizar actividades de trabajo por parte del Movimiento Nacional para la Reconstrucción Justa a través del Fondo de la Sociedad Civil de la Unión Europea. Es decir, el Observatorio de la Reconstrucción y sus actividades, nunca fueron financiadas ni con fondos gubernamentales ni de empresas privadas.
} 
razgo y organización en temas de políticas públicas y habitacionales. Nuestra posicionalidad en este proceso puede ser descrita como una actitud de "academia por demanda", como plantea Segato (2018). Pusimos nuestras capacidades académicas en comunicación con las necesidades, los saberes y las demandas de las comunidades afectadas, permitiéndonos co-producir conocimientos con numerosas organizaciones que surgieron durante este proceso. Nuestro equipo interdisciplinario se involucró con comunidades para debatir públicamente las tensiones que surgieron de los procesos de reconstrucción que experimentaban. $L$ a mayor parte de las veces se trató de un proceso gobernado desde una lógica de expertos de referentes norte-centrados, aplicando modelos tecnocráticos supuestamente universales y de comparabilidad internacional que poseen escasa sensibilidad sobre las formas de habitar situadas. Desde esta posición, nuestro trabajo hace eco de un creciente debate en el campo de los estudios urbanos, llevado en la actualidad por autores como Caldeira (2017), Delgadillo (2014), Robinson (2016), Roy (2016), Leitner \& Shepard (2016), entre otros.

Nuestro proceso de investigación se extiende por casi ocho años en diferentes etapas e intensidades (ver Figura $\mathrm{N}^{\circ} 1$ ). Nuestro equipo de trabajo concentró perspectivas desde las políticas públicas, arquitectura, urbanismo y ciencias sociales. Co-producimos información basada en decenas de entrevistas, grupos de discusión, contextos conversacionales en talleres, seminarios académicos y con autoridades públicas, así como en la participación en movilizaciones junto a las comunidades. Estos materiales fueron sistematizados y analizados para la elaboración de informes de apoyo de las demandas de las y los afectados, si bien no exclusiva con las comunidades de Constitución, ellas jugaron un rol significativo en el proceso.

El análisis que presentamos en el presente artículo se basa en información documental y, por sobre todo, en la perspectiva de los y las habitantes de Constitución. Con este fin, se presentan fragmentos de entrevistas que develan las valoraciones respecto a la formulación e implementación del Plan Maestro. Pero más que evaluaciones de un proceso de planificación, nos interesa plantear, al menos de forma introductoria, la experiencia de los y las habitantes con el resultado de este proceso. Para ello compartimos un relato sobre la experiencia de los residentes de Villa Verde con su ciudad ya reconstruida por este modelo de política pública.

Figura $\mathrm{N}^{\circ} 1$.

Principales etapas y técnicas de producción de información del proceso de investigación

\begin{tabular}{|c|c|c|c|c|}
\hline Años & 2010 & 2011-2012 & 2013-2015 & 2016-2018 \\
\hline
\end{tabular}

\begin{tabular}{lll} 
& Terremotoy tsunami & \multicolumn{2}{l}{ Reconstrucción } \\
Contexto & Inicio proceso de & Finalización de la \\
& reconstrucción & reconstrucción de las \\
Formulación PRES & principales obras \\
& urbanas y de vivienda
\end{tabular}




\section{Constitución como caso de estudio}

La evidencia ha demostrado que son las ciudades intermedias las que sufrieron más daños después de la catástrofe (Inzulza-Contardo \& Díaz, 2016; Inzulza et al., 2018). Junto a las importantes pérdidas materiales de servicios públicos y viviendas, estos centros urbanos experimentaron una acelerada transformación frente a los procesos de reconstrucción, tal como ha sido el caso de la ciudad de Constitución (VII Región del Maule).

Constitución es una ciudad que se ubica a $364 \mathrm{~km}$. de distancia al Sur de la capital nacional. En su costa, el tsunami afectó a más del $50 \%$ de las viviendas ubicadas en el plano de la ciudad (ver Figura $\mathrm{N}^{\circ}$ 2). En la comuna viven 46.068 personas (INE, 2017), de las cuales cerca de 10.000 fueron afectadas directamente por la catástrofe. De estos afectados, 304 familias fueron reubicadas a viviendas de emergencia, distribuidas en 8 asentamientos de emergencia. Ellas corresponden al $74 \%$ de las familias de la región que vivieron en esa condición.

Teniendo en cuenta la magnitud de los daños que sufrió la ciudad, se elaboró el PRES Constitución, transformándola en una ciudad "ícono" de la reconstrucción y la planificación territorial post-desastre.

Figura $\mathrm{N}^{\circ} 2$.

Zona de inundación por tsunami

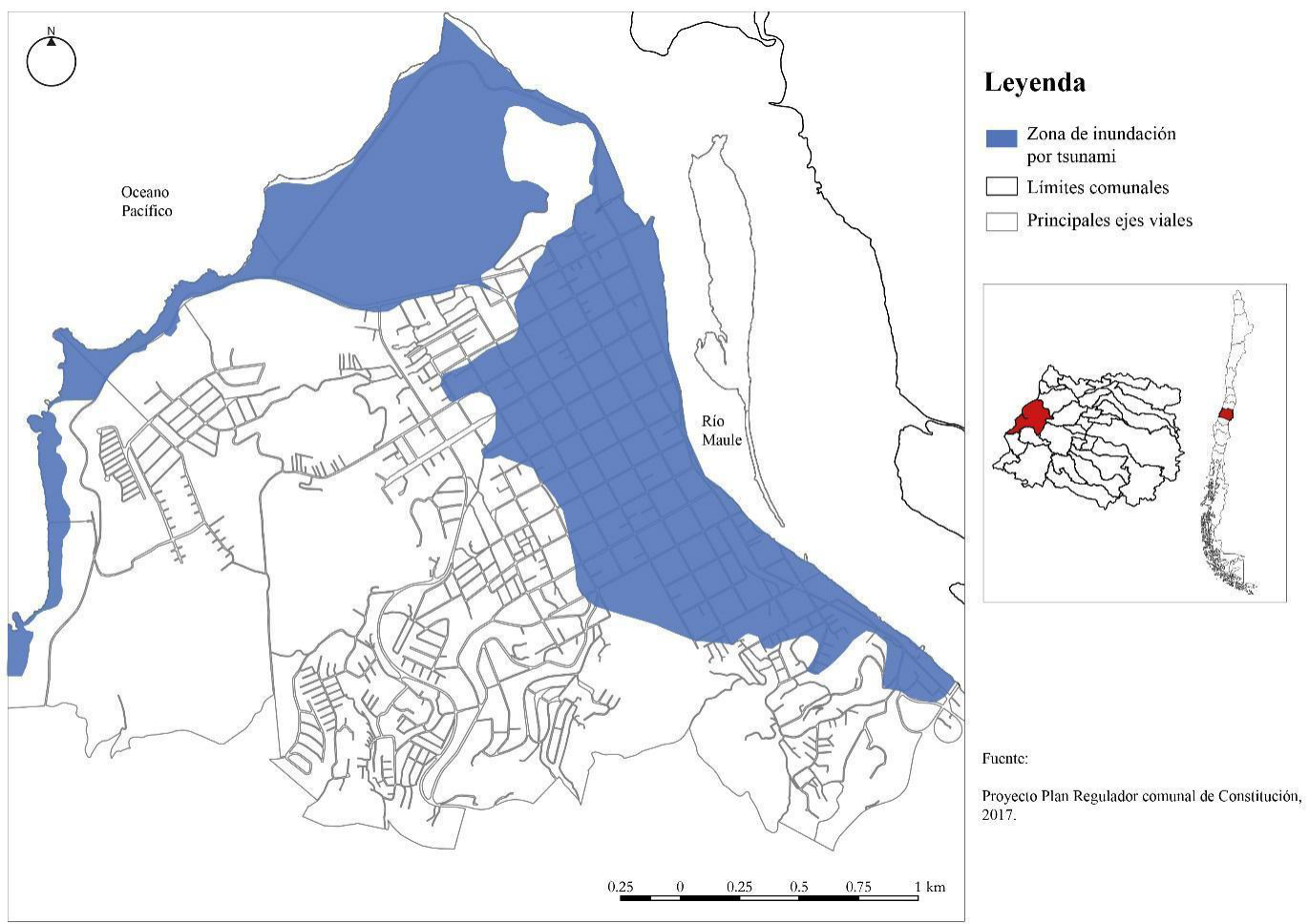

Fuente: Elaboración propia en base al proyecto de PRC de Constitución. 


\section{Planificación neoliberal en Chile y las APP post-desastre}

La neoliberalización de la planificación territorial en Chile se inició a finales de la década de 1970s, cuando la política nacional de desarrollo urbano determinó que el suelo no era un bien escaso y cuyo uso estaría definido por su rentabilidad. En términos generales se caracterizó por la disminución del rol regulador del Estado, la ampliación de las oportunidades de rentabilidad para agentes privados e inmobiliarios y la creación de un entorno construido sujeto a renovación, flexible y receptivo a la inversión de capital (López-Morales et al., 2012), todo bajo un modelo de inversión que se sostiene en las APP (Hidalgo et al., 2015). En síntesis, se trata de un modelo que promovió la ampliación de los campos de acción del capital privado en la ciudad. Se puede afirmar que la planificación neoliberal no tiene una imagen de ciudad específica que busque implementar, sino más bien se trata de un modelo de gestión. Las consecuencias de este proceso, en términos de morfología y función urbana, dependen de las estructuras institucionales y tipos de actores que se involucran. Esto es lo que Brenner y Theodore (2002) llaman el "neoliberalismo realmente existente" y que, por lo tanto, cambia de caso en caso.

Por un lado, el neoliberalismo chileno reemplazó los principios desarrollistas, entregando al interés privado el protagonismo de la economía. Asume que el mercado es el principal distribuidor de recursos para la inversión en la ciudad, dando forma a nuevos arreglos entre lo público y privado bajo la noción de gobernanza (De Mattos, 2004). Por otro, esta gobernanza neoliberal reproduce una gestión que fragmenta la vida cotidiana de las personas en los territorios, al organizar las prácticas de planificación en diferentes escalas con débil conexión entre ellas (local, regional y nacional) y de forma sectorial (transporte, servicios y viviendas por separado) (López et al., 2013). Los impactos de este proceso han sido ampliamente documentados a nivel de las políticas habitacionales (Ducci, 2002; Tapia, 2011; Hidalgo 2019; Fuster-Farfán, 2019) y en menor medida en el campo de la movilidad y transporte (Jirón y Mansilla, 2014; Ureta, 2014). Es justamente en estas dos áreas donde la relación entre lo público y privado ha tomado nuevos balances, orientados hacia un empresarialismo urbano (Harvey 2018; Bustos et al., 2019).

Según Revet \& Langumier (2013), no se puede reducir la gestión post-desastre como un mero conjunto de instrumentos técnicos o de medidas administrativas, pues esto lleva a considerarlas apolíticas. En este sentido, utilizar el modelo de APP en la planificación territorial no debe ser visto como un proceso neutro y puramente técnico como fue anunciado por las autoridades de la época. Las APP no se limitan a la administración, seguimiento y gestión del proceso, sino que también implican una acción de posicionamiento del Estado respecto de sus responsabilidades y de a quiénes convoca para encabezar la planificación territorial. Según Marty et al. (2006), las APP son formas de asociación de los sectores público y privado a través de contratos específicos (elemento de distinción con privatizaciones y subcontratación) y de inversiones financiadas total o parcialmente por el proveedor privado, cuyo pago (realizado por usuarios o la autoridad pública) cubre la amortización de estas inversiones y su explotación. En el caso de la reconstrucción chilena post-desastre, las APP pretendieron garantizar eficacia e innovación en las respuestas ante la catástrofe (Vergara et al., 2016). Sobre esto último, para Pliscoff \& Araya (2012), las APP suelen ser consideradas innovadoras en sí mismas ya que generan nuevas formas de gestión, pero esto sólo supone un cambio organizacional. Para estos autores, el cambio organizacional ocurre dentro de un paradigma determinado, mientras que una APP sería gatilladora de innovación cuando implique un quiebre de paradigma, generando algo nuevo. 


\section{EI PRES de Constitución: la APP y la triada decidores-gestores- financistas}

El Ministerio de Vivienda y Urbanismo (MINVU) instruyó a las administraciones regionales a que desarrollasen planes de reconstrucción territorial. Estos planes adquirieron diversas formas dependiendo del lugar donde se implementaron: PRES, Planes de Reconstrucción Urbana (PRU) y Planes de Reconstrucción en Borde Costero (PRBC). Cada uno de ellos se administraron a través de APPs. Este modelo basado en el diseño de Planes Maestros propuso que la administración del territorio se desplace desde el aparato público hacia una forma de gobernanza basada en la negociación entre privados y actores de interés presentes en el territorio, pretendiendo la despolitización del proceso de planificación y ordenamiento territorial (Parker, 2009). El PRES Constitución se propuso como un instrumento de "urbanismo integral", combinando la dimensión geográfica y material del riesgo, con la participación ciudadana como fuente de validación ${ }^{10}$. Respecto de este último componente, el PRES realiza diversas actividades: consultas ciudadanas, buzones de propuestas, y "foros híbridos", que pretendían equiparar discursos técnicos y ciudadanos para la toma de decisiones. Las metodologías de estos instrumentos con "innovadores" nombres, no obstante, no fueron validados por actores claves de la comunidad.

Aunque se presentaba como participativo y pertinente al territorio, para Mella (2012), el modelo de reconstrucción del Gobierno de Piñera tuvo un fuerte componente centralista en el sentido que se construyó una triada entre el gobierno central, el gobierno regional (nombrado directamente por el presidente), y las corporaciones privadas. Para el autor, las APP se convirtieron en un triángulo entre decisores, gestores y financistas que apenas consideraban los gobiernos locales y su población. De esta forma, podían operar de manera directa sin pasar por las municipalidades, constituyendo un verdadero by-pass político y estratégico. Esto tuvo un impacto inmediato en la ciudad de Constitución.

En el espíritu de desarrollar un plan bajo el modelo de las APP, el conglomerado Celco-Arauco encabezó el proceso de reconstrucción y planificación territorial a través del diseño del PRES. Arauco fue una empresa pública hasta 1979, privatizada en el contexto de la dictadura. Actualmente, es un actor principal de la industria forestal chilena y la segunda empresa de celulosa más grande de América Latina. La planta de producción de celulosa en Constitución es la más antigua del conglomerado. Muchos habitantes de Constitución prestan sus servicios en ella, tanto directa como indirectamente. La ubicación de esta planta industrial es estratégica en la ciudad, encontrándose a solo a unos metros de su centro cívico y ocupando una parte importante del borde costero y borde río de Constitución.

La inversión más publicitada del PRES (incluso más que las mismas obras de reconstrucción) fue la contratación como asesor del arquitecto socio y co-fundador de la oficina de arquitectura autodenominada "Do Tank" Elemental S.A, Alejandro Aravena, quién había logrado exposición pública nacional e internacional por su propuesta de diseño incremental en proyectos de vivienda social. Entre las distintas propuestas para reconstruir Constitución bajo un enfoque de "urbanismo integral" (según establece el PRES), se encuentra el proyecto habitacional Villa Verde. Este

10 Esto se refleja en el video corporativo del PRES en el sitio https://www.youtube.com/watch?v=5p_MBKCp4cQ (consultado en marzo 2020) 
proyecto de viviendas pública representa la "integralidad" en la medida que combina la participación de los habitantes, la construcción en madera (más barata, eficiente y sustentable según el PRES) y la localización en una zona no expuesta a un tsunami. Si bien se presentó como un proyecto ad-hoc a la reconstrucción post-desastre, en realidad ya estaba preconcebido desde 2009 para los trabajadores de Celco-Arauco. Así, no sólo la relación Elemental y Celco era previa a la catástrofe, también en esta triada fue muy importante la relación directa entre el equipo de Elemental y algunos de los principales encargados del proceso de reconstrucción del primer Gobierno de Sebastián Piñera"1.

Habiendo entronizado a Aravena como un experto incontestable, y formando equipo con un grupo de tecnócratas de alto nivel, el PRES Constitución obtuvo rápidamente una legitimidad muy difícil de cuestionar gracias a su perfil técnico y en apariencia apolítico. Esta última condición se afianzó con la participación del Instituto de Sociología de la Universidad Católica en las actividades de vinculación con la ciudadanía. Sin embargo, más allá de la legitimidad de la triada de decidores-gestores-financistas para actuar, lo que se logró fue legitimar la intervención en la zona de catástrofe formuladas con anterioridad al $27 \mathrm{~F}$ y sin ninguna participación ciudadana en su génesis.

El rol que jugaron este grupo de tecnócratas y expertos no fue una nueva fórmula en las políticas públicas chilenas. Según Silva (2011), durante la transición política chilena, la ideología tecnocrática se mezcló con el ideario de la democracia, dando forma a una "democracia tecnocratizada", donde los problemas sociales se traducen en términos técnicos y donde la aparente despolitización se convirtió en un núcleo central del modelo chileno. En este sentido, los equipos que participaron al interior del MINVU o asociados a él, como el caso de Elemental, responden a esta lógica de construcción de políticas públicas en Chile. En efecto, Olavarría (2013) señala que se produce la convergencia de tres factores: un actor político con poder suficiente para determinar una intervención; un grupo de técnicos capaces y validados por el actor político; una coyuntura que permita a ambos actores relacionarse para intervenir ante un problema público. Si bien el proceso de reconstrucción se presenta como participativo, y una de las innovaciones estaría dada por la co-construcción de la planificación post-desastre, lo cierto es que la triada no representa un quiebre con el clásico modelo top-down de políticas territoriales. Por el contrario, como veremos más adelante, la participación de damnificados y habitantes del territorio se tradujo a una participación consultiva de medidas ya consideradas como posibles soluciones para enfrentar la reconstrucción. Sostenemos entonces que esta APP no fue en realidad un dispositivo innovador, puesto que no rompe con el paradigma ya impuesto, sino que se trata de un cambio organizacional.

En este sentido, la acción del Estado chileno ante catástrofes socionaturales es un ejemplo claro de dominación tecnócrata aplicada a políticas públicas. Las justificaciones técnicas y la búsqueda de eficiencia afectan negativamente el orden social de los territorios intervenidos y se encuentran en el origen del conflicto de los habitantes con el Estado en procesos de reconstrucción (Ugarte \& Salgado, 2014). Esto genera que la ciudadanía se transforme en sujeto de

Dentro del MINVU un equipo de tecnócratas fue estratégico: Pablo Allard, socio fundador de Elemental, se transformó en el Coordinador Nacional de Reconstrucción Urbana del MINVU; Pablo Ivelic, asume como Coordinador del Programa de Reconstrucción de Vivienda MINVU; Andrés lacobelli, fue nombrado Subsecretario MINVU y Claudio Seebach, asumió como jefe de la División de Coordinación Interministerial de la Secretaría General de la Presidencia. Todos habian compartido experiencias universitarias y profesionales anteriores al proceso de reconstrucción (La Segunda, 2019) 
resistencia de estas estrategias de intervención altamente técnicas, lo que finalmente redunda en la organización de dos movimientos multinivel de oposición al proceso de reconstrucción post 27F: el Movimiento Nacional por la Reconstrucción Justa MNRJ (ubicado en diversas regiones) y RedConstruyamos (asentada en la VIII región). Las comunidades de Constitución se unieron tempranamente a estos colectivos.

\section{EI PRES y la participación consultiva: el usuario-cliente para la gober- nanza urbana}

De acuerdo a los lineamientos entregados por el Gobierno de Chile, los Planes Maestros debían responder a los principios de sostenibilidad y participación ciudadana, pero no declararon explícitamente su vinculación con los instrumentos de planificación territorial formales ya existentes. En general, para el proceso de reconstrucción post 27F, las APP de los Planes Maestros tuvieron, en principio, una percepción positiva por parte de la población, en particular durante el período de urgencia. Sin embargo, a medida que fueron aplicándose estos instrumentos y los privados comenzaron a hacerse más presentes, surgieron las primeras críticas. Esto podría explicarse principalmente por la implementación de actividades de participación poco claras. En algunos casos los PRES implementaron consultas sobre el tipo de vivienda al que podían acceder las familias, en otros sobre la validez de los proyectos ya formulados en el contexto del PRES.

Sobre el rol de Celco, el PRES Constitución profundizó las desigualdades de poder, pues el proceso se mantuvo en manos de los actores que ya tenían una posición dominante sobre los habitantes e, incluso, sobre el mismo gobierno local (Contreras \& Beltrán, 2015). En una entrevista realizada a una vocera del Movimiento Nacional por la Reconstrucción Justa de Constitución, se evidencia la preponderancia y autonomía del actor privado en desmedro de la democracia local:

Vocera MNRJ: Yo he encontrado como ausente al Municipio, quizá porque antes era un Gobierno opositor al Gobierno, o sea era un Municipio de Concertación y el Gobierno es de derecha. Como que se hizo un bypass con el Gobierno Local. EI SERVIU [Servicio de Vivienda y Urbanización] aquí tenía autonomía. Acá no tenemos plan regulador actualizado, no tenemos el instrumento que localmente podría validarse. Entonces ellos operaron mucho, aquí entre el Gobierno y Arauco tomaron muchas decisiones y el Gobierno local ahí se mantuvo en silencio.

Entrevistadora: En ese sentido, ¿qué actores han sido los más claves que han participado en la reconstrucción?

Vocera: Arauco, Arauco definió los lineamientos a seguir en la ciudad.

E: ¿Junto con el Municipio?

Vocera: $Y$ en ese sentido el Municipio yo considero que se mantuvo en silencio. En silencio porque crearon esta figura del PRES [...] entonces era como alianzas, y entre Arauco y el Gobierno definieron lo que había que hacer con esta comuna ${ }^{12}$. 
Bexell \& Mörth (2010) destacan que organismos internacionales en general promueven la participación del sector privado para enfrentar crisis, no obstante, este involucramiento no necesariamente aporta a la legitimidad política de las intervenciones. Esto apareció constantemente en nuestro trabajo de campo, tanto en entrevistas como en focus group. Los afectados por el desastre perciben a las APP de reconstrucción como una herramienta para establecer una planificación ad-hoc a las necesidades de Celco. A pesar que existieron espacios de discusión y de votación para pensar el futuro de la ciudad, éstos fueron considerados como un mecanismo para validar el PRES y legitimar las decisiones ya tomadas por otros actores:

Entrevistadora: ¿Han oído hablar de PRES?

Habitante 1: No es nada poh, no es nada.

E: ¿Por qué no es nada?

H2: Porque hacen exposiciones y, en última instancia, nada concreto, nada, nada, nada, es solo bla bla bla

H3: Nos preguntaron: "¿Qué le parecerá Constitución para el futuro?" ¿Qué ganaba diciendo que me gustaba así? Si al final de cuentas, arman un proyecto y lo presentan

H1: ¡Y lo hacen como quieren! Entonces, ¿para qué sirve el PRES?

H4: EI PRES fue manipulado, porque al final, podiamos opinar sobre lo que ellos querían

H3: Entonces, por ejemplo, habia una pregunta sobre el parque: "¿Quieres un parque para Constitución?" o "¿Quieres que la ciudad siga así?" Tuvimos un gran desastre, nadie quería que la ciudad se quedara como estaba...13

Tanto la percepción de la vocera local como de quienes fueron consultados a propósito de su participación en el PRES, refleja uno de los principales problemas de las APP para la democracia local. Como señala Barnezet (1995), el objetivo de la eficiencia que persiguen este tipo de alianzas termina por generar constantemente ofertas de servicios públicos para usuarios-clientes, olvidando así que los habitantes de los territorios si bien son usuarios de los servicios y bienes que se entregan en el marco de estas APP, son por sobre todo sujetos políticos.

\section{Villa Verde como materialización de la APP en el territorio}

En términos de planificación territorial y ordenamiento del territorio, Constitución cuenta con un Plan Regulador Comunal (PRC) del año 1987, el cual no considera estudios sobre riesgo ni regula los sitios que hoy están urbanizados. El PRES en vez de priorizar la planificación territorial

Grupo focal, Constitución, 27 julio 2013 
y actualización del PRC, se materializó en un Plan Maestro cuyas obras se centraron en la recuperación del espacio público y en la construcción de viviendas para la población damnificada. La única referencia del PRES a la planificación territorial de Constitución es la necesidad de densificación y de expansión del límite urbano. En la Figura $N^{\circ} 3$ se identifican los proyectos de vivienda construidos en el marco del PRES, evidenciando cómo éstos se utilizaron como un instrumento de expansión de la ciudad.

Figura $\mathrm{N}^{\circ} 3$.

Conjuntos de viviendas sociales para damnificados construidos en el marco del PRES

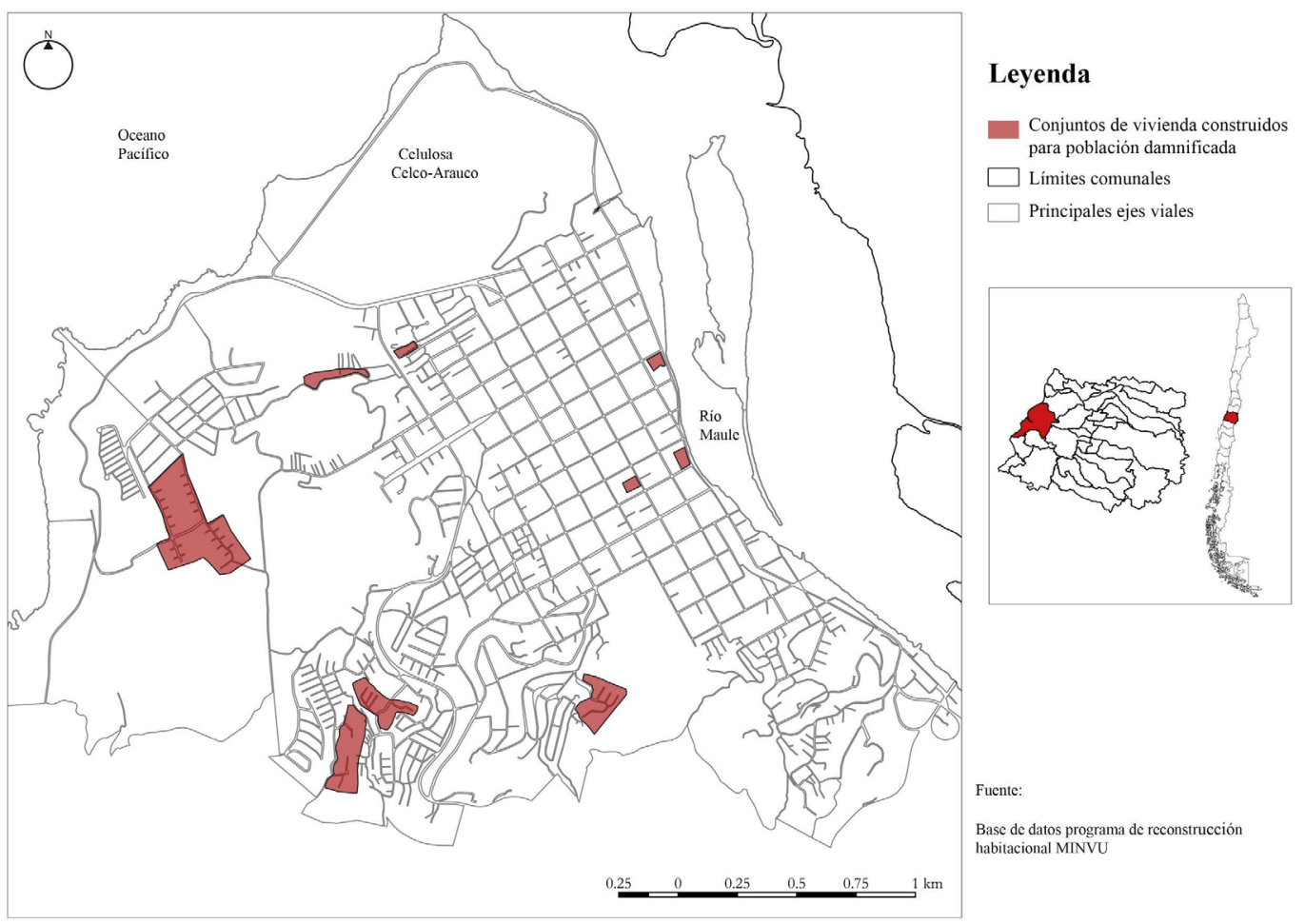

Fuente: Elaboración propia.

EI PRES desvincula las intervenciones urbanas de las formas de habitar de las personas, es decir, actúa sin considerar las experiencias de sus habitantes. Para este fin se analizará el proyecto más emblemático del PRES: el conjunto de viviendas sociales Villa Verde para población damnificada.

Villa Verde es un proyecto de 484 viviendas de $57 \mathrm{~m} 2$ ampliables hasta $85 \mathrm{~m} 2$ para familias damnificadas por la catástrofe, adquiridas a través de subsidios entregados por el MINVU en un terreno de propiedad de Celco y construidas en madera, material comercializado por la misma forestal. La tipología de las viviendas se inspira en el modelo de vivienda progresiva comercializado por Elemental. Su diseño es flexible, de modo que sus ocupantes puedan intervenir los espacios según sus necesidades, lo cual transmite una sensación de participación sobre la producción del hábitat. Se trata de construir, literalmente, "medias casas" con el fin que las familias, con sus 
propios medios y recursos, construyan la casa completa. Este es el proyecto del PRES que requirió mayor participación activa de los habitantes de Constitución.

\section{Disociación entre la tecnocracia urbana y la experiencia de los habi- tantes}

Clara y su familia se fueron a vivir a uno de los ocho asentamientos de emergencia que se construyeron en Constitución. En la espera de soluciones definitivas, conocieron distintos proyectos de vivienda que no se concretaron, pero hubo uno que marcó la diferencia: era el proyecto del "arquitecto famoso". Ese arquitecto que contrató la empresa de celulosa más grande de la región. Sabían que el proyecto iba a funcionar, la empresa no podía fallar, así que se organizaron para conseguir algunos cupos y vivir en esas casas.

"Cuando veíamos el terreno, sabíamos que sería una de las construcciones más grandes de la zona". Clara no se equivocó. El proyecto generaba incertidumbre porque la idea del "arquitecto famoso" era que las casas estuvieran construidas "a la mitad". El 27 de septiembre de 2013 la espera terminó: les entregaban las llaves de sus casas.

Villa Verde es uno de los pocos conjuntos de vivienda construidos post terremoto en la comuna que se componía plenamente por casas. Los habitantes valoran las casas por poseer atributos como la privacidad de los espacios y la existencia de patios, jardines y estacionamientos. Por esta razón es que la especulación sobre quiénes accederían a Villa Verde se transformó en un tema relevante entre las familias damnificadas. Esto a pesar de las aprehensiones que existían sobre su localización en la periferia de la ciudad y la incertidumbre respecto de la conectividad a los servicios y al plano.

A pesar que muchas de estas familias vivían en asentamientos de emergencia, los escasos recursos que tenían los juntaban (en el caso de los materiales) o ahorraban (en el sentido monetario). Ellos sabían que las casas vendrían "a la mitad", por lo que sería un desafío "completarla". Completarla no sólo con equipamiento doméstico, sino que con el diseño y la construcción de una nueva estructura.

\section{Participar a través de la autoconstrucción: el desafío de "rellenar el espacio"}

El proyecto emblema del PRES requería de la participación activa de las familias para su éxito. Por esta razón, la autoconstrucción y la capacidad de los habitantes para movilizar sus recursos fue clave para el modelo de reconstrucción y ordenamiento territorial basado en proyectos.

Para ninguna familia del mundo popular latinoamericano es nuevo autoconstruir su vivienda. Desde el punto de las políticas de vivienda se puede iniciar un recorrido con el paradigmático trabajo de John Turner en las décadas de 1960s y 70s (1976). El caso chileno ha sido históricamente testigo de grandes asentamientos que fueron producto de la construcción popular y organizada. A lo largo de décadas se han desarrollado programas habitacionales orientados a la autoconstrucción, tales como los programas de lotes con servicio o de vivienda progresiva. En el caso de 
Constitución observamos que gran parte de su borde río, muy asociado a la actividad pesquera, es uno de los barrios (La Poza) autoconstruidos más antiguos, valiosos y reconocidos de la ciudad. A esto se suma la importante presencia de la industria maderera en la zona, donde el trabajo de este material está arraigado en sus habitantes. Se trata de una herencia de saberes sobre la autoconstrucción que es parte de la cultura popular chilena, y especialmente de la maucha ${ }^{14}$.

El esfuerzo individual de las familias es clave para el éxito de Villa Verde: el ahorro y el endeudamiento fueron los recursos más utilizados para su concreción. Los vecinos prepararon su llegada ahorrando con anterioridad o recurriendo a créditos bancarios para poder financiar la "otra mitad". El resultado fue exitoso y es evidente a simple vista: casi el 100\% de las viviendas están ampliadas. En un contexto donde las periferias urbanas tienden a la homogeneidad, este tipo de experiencias son valoradas por sus habitantes debido a la posibilidad que tienen para adecuar las viviendas a sus necesidades. Sin embargo, esto ocurre sólo cuando las personas individualmente cuentan con las condiciones materiales para realizar este tipo de intervenciones. En la Figura N4 se puede identificar que sólo una vivienda de una fila de nueve está sin construir, lo cual es un panorama generalizado en el resto del conjunto:

Figura N4.

Vivienda sin completar en Villa Verde

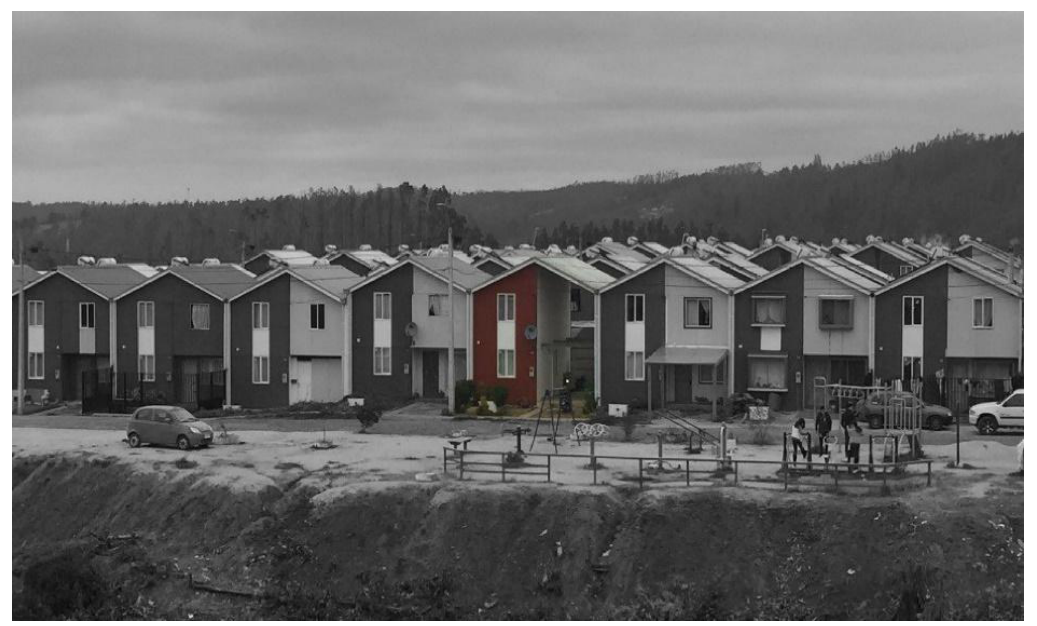

Fuente: Elaboración propia.

\section{Vivienda sin ciudad: la experiencia de los habitantes}

Una vez instalados comienza la nueva vida. Antes de la catástrofe Raúl caminaba hacia su trabajo y no demoraba más de 15 minutos. Esto le permitía tener más tiempo de descanso y la posibilidad de almorzar en su casa con Rosa, su pareja. En Villa Verde el escenario cambió: camina 45 minutos, debe preparar almuerzo y calentarlo en su trabajo y, cuando es invierno, tomar un colectivo ${ }^{15}$ de regreso a su casa. Raúl nos indica que a pesar de ser más rápido el colectivo

15 Un colectivo es un medio de transporte en Chile que es compartido por cuatro personas. Sus tarifas son más costosas que otros transportes públicos como el metro y los buses. 
para llegar al centro de Constitución, los costos que debe asumir no estaban presupuestados. Esto porque después del 2010 su presupuesto familiar se mantuvo en el mismo monto, debiendo vivir con el mismo presupuesto, pero con más gastos. "Tengo cerca de 70 años y estoy cansado", nos dice. El precio del colectivo es de $\$ 500$, y calculando los días laborales (5), sólo una persona gasta $\$ 5.000$ a la semana, es decir, $\$ 20.000$ al mes en un país donde el sueldo mínimo es de $\$ 326.500^{16}$. Esto en un escenario hipotético donde una persona viaja hacia el centro de la ciudad (donde están concentrados todos los servicios) sólo una vez durante cinco días. Junto con el impacto económico, su vida cotidiana se tuvo que reorganizar en términos del compartir familiar y descanso.

A pesar que a gran parte de los cerros de Constitución se puede acceder en microbús (con precios mucho más accesibles), hasta la fecha Villa Verde no cuenta con esa posibilidad. Así, la responsabilidad de conectar a los habitantes con la ciudad recae en los taxis colectivos. En una conversación con Ramón, chofer en Villa Verde, nos señaló las instrucciones que tienen para transitar por el lugar: “Usted sabe que estas son viviendas sociales, entonces es una población peligrosa. Nosotros debemos venir sólo hasta las diez de la noche y no doblar hacia el interior, hacia la parte más alejada". Ramón nos relata el estigma que portan las viviendas sociales y las estrategias que ellos asumen para enfrentarse al "peligro".

En varias ocasiones caminamos de noche y nos percatamos que las calles son tranquilas para los peatones. Si bien la iluminación no es óptima, la visibilidad es suficiente para transitar. Un sábado a las once de la noche casi no había personas en la calle, por lo que no sentimos esta amenaza relatada por Ramón. Ahora bien, independiente de su perspectiva, pudimos comprobar que efectivamente no existe transporte nocturno, por lo que en caso de cualquier emergencia los vecinos deben gestionarlo individualmente. También pudimos corroborar la existencia de este límite autoimpuesto por los colectiveros. Recorrimos de día y a distintas horas el sector sur de Villa Verde y sólo pudimos ver un colectivo que traspasó el "límite". Le preguntamos por qué lo había hecho y nos señaló que la persona se lo había pedido, pero que él estaba ahí "bajo su propia voluntad".

Un día viernes de invierno esperamos el colectivo desde el centro de Constitución a las ocho de la tarde. Estuvimos en el paradero por más de dos horas; ningún vehículo transitó. Las personas con las que nos encontrábamos en el paradero decidieron caminar. Evidentemente no era lo mismo bajar desde la Villa hacia el centro caminando que subir el cerro en el sentido contrario. A la mitad del camino, un chofer de colectivo que sube a otro cerro nos preguntó si necesitábamos que nos llevara y nos ofreció su ayuda a cambio de pagar $\$ 1.500$ cada uno ${ }^{17}$. Decidimos aceptar su oferta y pagar. Es por eso que Rosa nos dice "las tardes aquí son un toque de queda voluntario".

En una conversación con Clara le preguntamos qué hacía ella si debía bajar al centro de noche o de madrugada, lo cual es muy común para quienes viajan a la capital regional, Talca, o a la capital nacional, Santiago. Ella nos respondió: "tenemos nuestro propio Uber". El "Uber" de Clara es un antiguo colectivero que realiza servicios de transporte informal: "Albertito, ¿puede venir a buscarnos mañana a las 5 de la madrugada? tenemos que viajar". De este modo Clara 
reservaba una hora con su "Uber". Alberto llegó puntual a la hora requerida. Al preguntarle sobre este servicio de "Uber" nos dijo que como las personas de Villa Verde no tenían transporte de noche o éste era muy limitado, decidió trabajar de manera particular. Así puede cobrar los mismos precios de un taxi.

Si bien el conjunto cuenta con establecimientos de educación pública para la primera infancia, la escuela más cercana es pagada, por lo tanto, sólo van aquellos niños que tienen recursos para hacerlo. Al respecto Pamela nos dice: "el colegio más cercano a la Villa es particular subvencionado. Los demás están todos abajo, en el plano, y los más cercanos están a media hora de camino a pie y alrededor de diez minutos en auto. Tenemos que caminar, porque de lo contrario para nosotros es casi imposible asumir esos costos".

\section{PRES: Modelo nuevo, resultados antiguos}

EI PRES como APP permitió a Celco a través de Elemental, diseñar lo que sería el "nuevo Constitución", posición de poder a la que, en otro contexto, no hubiera podido acceder un actor privado. Planteamos que posicionar a los privados en el ciclo de políticas públicas desde la elección de hipótesis de intervención pasando por el diseño y hasta la implementación de ésta, es lo nuevo del modelo para la planificación territorial. Sin embargo, esto reviste un cambio organizacional y no una innovación, pues si bien modifica las relaciones de poder para la planificación, mantiene y refuerza el paradigma neoliberal ya existente.

Lo que parecía una nueva gobernanza tampoco es nuevo, pues la triada a la que se refiere Mella (2012) sigue siendo un modelo de política top-down (diseñado por expertos con decidores de política a nivel central), haciendo que la relación del PRES con los habitantes fuese clientelar y consultiva, consolidando una planificación sin habitantes. Como se expresa en el caso de Villa Verde, el proyecto fue desarrollado sin tomar en cuenta la compleja trama de la vida cotidiana de los y las habitantes, sin considerar las fuentes laborales, el acceso a servicios, familia y cuidados, presupuestos, entre otros, que dan forma al habitar. Esta consideración, supone concebir a las personas como sujetos políticos (Ugarte et al. 2015), cuyos conocimientos son centrales para la planificación territorial. La evidencia ha demostrado la importancia del involucramiento activo de los habitantes en los procesos de reconstrucción, en la medida que los empodera y hace más resilientes ante nuevas catástrofes (Schilderman \& Lyons, 2011).

Al analizar en profundidad el caso de Villa Verde, tanto en su gestión como en su ocupación, evidenciamos la disociación entre los intereses corporativos y las formas de habitar de la población. A esta última se le pone en una posición receptiva de las prácticas de planificación territorial, sin reconocer sus saberes sobre las dinámicas cotidianas de la ciudad. Los habitantes surgen como actores y promotores en la producción de su hábitat a través de la conclusión de sus "medias casas", basado en el esfuerzo y capacidades individuales, dejando en evidencia el proyecto político e ideológico detrás de un proceso aparentemente técnico.

El impacto de este modelo para la ciudad fue la consolidación de nuevas periferias urbanas donde se relocalizó a la población más afectada por la pérdida de sus viviendas. Se trata de un 
resultado que no es nuevo en las políticas urbano-habitacionales chilenas, donde la población desfavorecida es dependiente de un sistema que basa su accionar en la construcción de una ciudad expandida, periférica y dependiente de su relación con el centro (Hidalgo et al. 2008). En la Figura $\mathrm{N}^{\circ} 5$ se presenta el emplazamiento de Villa Verde en relación al equipamiento de salud y de educación. Se observa que las escuelas públicas se concentran en el plano y en otros cerros. Lo mismo ocurre con los establecimientos de salud pública. Así, en el caso de una ciudad intermedia como Constitución, se siguen replicando antiguas prácticas de planificación territorial metropolitanas, donde se construye vivienda sin ciudad.

En la misma Figura $N^{\circ} 5$ se identifican los focos de incendios forestales ocurridos el año 2017. Si bien el PRES se propuso como un modelo de reconstrucción sustentable e integral, se observa cómo los terrenos adyacentes a la Villa fueron afectados por un incendio ese año. Teniendo en cuenta que gran parte del suelo de Constitución es de uso forestal (Díaz-Hormazábal \& González, 2016), la planificación en esta zona exige un "pensamiento resiliente" que tenga en consideración los elementos ambientales, naturales y sociales del territorio (Villagra et al., 2016). De lo contrario, se estaría poniendo a salvo a la población frente a un tipo de riesgo de desastre, como son los maremotos, pero exponiéndola a otros. No obstante, Constitución no cuenta con una planificación territorial que considere estas transformaciones y su exposición a nuevos riesgos.

Figura $N^{\circ} 5$.

Emplazamiento de Villa Verde en relación a los servicios públicos y riesgos de incendio

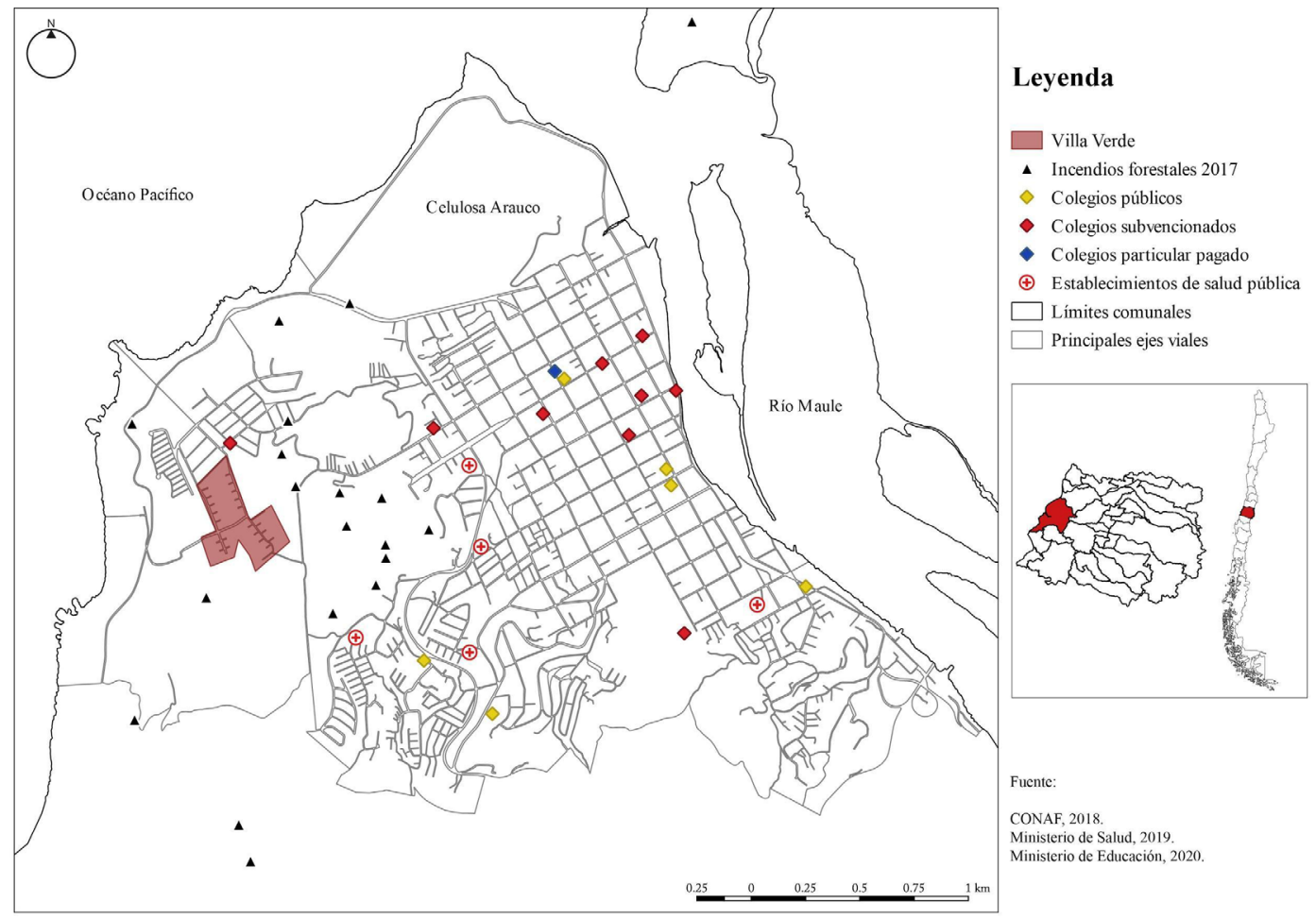

Fuente: Elaboración propia. 


\section{Conclusión}

Los desastres pueden ser ventanas de oportunidad para transformar las políticas regulares (Olavarría, 2007) a fin de generar cambios significativos en los balances de poder y cambiar las trayectorias de desarrollo de los territorios. El caso del PRES Constitución muestra que esta oportunidad más bien se orientó a ampliar la relación entre privados y Estado a favor de una mayor incidencia de los primeros sobre el ciclo de política pública. La APP que surge de este proceso reproduce el camino de una planificación territorial a favor de los intereses privados, desconectado de las formas de habitar e intereses y aspiraciones de su población, dando paso a la concepción y construcción de viviendas sin ciudad.

Tal como muestra el caso de Villa Verde, las comunidades de la ciudad de Constitución experimentan el desdén de las instituciones públicas y privadas por sus capacidades y aspiraciones, instrumentalizadas como clientes en el proceso de formulación y con cambios significativos en sus vidas cotidianas como efecto de las soluciones realizadas. En esta planificación sin habitantes, el rol de las personas se reduce, una vez, más a concluir por sí mismas sus viviendas, sus proyectos de vida y su territorio.

Teniendo en cuenta que los resultados del PRES no distan mucho de lo que hubiese sido un proceso llevado a cabo por mecanismos regulares de política pública, es válido preguntarse por qué se muestra como un caso exitoso e innovador. La respuesta puede tener dos vertientes, que confluyen en el hecho que la ciudad se reconstruye para la reactivación económica cuyo foco no es la planificación territorial. Primero, la oportunidad de consolidar un tipo de APP que hasta la fecha no se había implementado en nombre de la planificación territorial. Cuestión ya planteada por Savas (2000) en relación a presentar las APP como nueva forma de colaboración, pues así se permitiría generar espacios de implementación de iniciativas que, bajo el enfoque directo de privatización o externalización, producirían rechazo y asperezas en ciertos grupos de la sociedad. En estos términos, este es el verdadero experimento del PRES Constitución, cuyas repercusiones superan a la experiencia en sí misma. En efecto, la alianza entre Elemental y Arauco se mantiene y abre nuevos espacios de negocio y de construcción de APP en las políticas urbano-habitacionales ${ }^{18}$. Segundo, es posible hipotetizar que este PRES ha tenido un componente comunicacional más relevante que su supuesta innovación en la forma de enfrentar la planificación territorial. Lo que queda de un proceso como el de Constitución es un capital reputacional de los actores privados involucrados. Por parte de Arauco y sus políticas de responsabilidad social empresarial y por parte de la oficina Elemental como generadora de propuestas "innovadoras" en la planificación territorial.

Desde el terremoto y tsunami del 2010 se han desarrollado numerosas iniciativas académicas y de la sociedad civil $^{19}$ que han alimentado la reflexión sobre la prevención, recuperación y reconstrucción post desastres. El análisis crítico respecto a las acciones en términos de la planifica-

\footnotetext{
18 La crisis subprime había impactado a Arauco en 2009, produciendo grandes pérdidas en la exportación de madera y celulosa (Informe AmCham, 2009), pero el modelo generado a partir del trabajo de reconstrucción con Elemental permitió expandir el nuevo nicho a viviendas sociales construidas con material también fabricado por Arauco, lo que incluso ha llegado a ser premiado como buena práctica de RSE (Pacto Global, 2015).

19 Desde la academia se han generado centros inter o transdisciplinarios sobre desastres como CITRID (Universidad de Chile), CIGIDEN (FONDAP de la Pontificia Universidad Católica), y desde la ciudadanía, iniciativas como Proyecto DIVERSILIENTES, Fundación Proyecta Memoria, etc.
} 
ción urbana y territorial debe ocupar aún un rol central en ellas, por la capacidad integradora que presenta el territorio para abordar las formas de habitar de las personas. Especialmente desde finales del año 2019 ha emergido un renovado espíritu crítico sobre políticas públicas y formas de organizar el poder que han incrementado las desigualdades en el país en las últimas décadas. No nos cabe duda que los efectos de la reconstrucción territorial implementada desde el 27F ha jugado un rol en la experiencia de desigualdad de muchas personas y comunidades damnificadas que, pese a la supuesta acción diligente e innovadora por parte del Estado, han visto mermada su calidad de vida.

Los desastres socio-naturales en Chile ocurren con regularidad y en cada uno de ellos se presenta una nueva oportunidad para innovar en políticas y acciones que mejoren las condiciones de vida de las personas. Las intervenciones en el territorio dejan ver sus impactos y efectos en el mediano y largo plazo, y es ahí donde nuestro texto quiere aportar, superando la visión centrada en la emergencia con la que se suele analizar estos procesos.

\section{Referencias bibliográficas}

ARCHER, D. \& BOONYABANCHA, S. Seeing a disaster as an opportunity - harnessing the energy of disaster survivors for change. Environment and Urbanization, 2011, № 2, p. 351-364. doi: https:// doi.org/10.1177/0956247811410011

ARENAS, F., LAGOS, M. \& HIDALGO, R. Los riesgos naturales en la planificación territorial. Temas de la agenda pública, 2010, No 39, p. 1-11. Disponible en internet: https://politicaspublicas.uc.cl/ wp-content/uploads/2015/02/los-riesgos-naturales-en-la-planificacion-territorial.pdf

BARNEZET, S. Partenariat public-privé et démocratie locale. Revue d'économie financière, 1995, No 1, p. 347-354.

BEXELL, M. \& MÖRTH, U. Democracy and Public Private Partnership in Global Governance. New York: Palgrave Macmillan, 2010.

BORSDORF, A. Hacia la ciudad fragmentada. Tempranas estructuras segregadas en la ciudad latinoamericana. Scripta Nova. Revista de geografía y ciencias sociales, 2003, No 146. Disponible en internet: http://www.ub.edu/geocrit/sn/sn-146(122).htm

BRENNER, N. \& THEODORE, N. Cities and the Geographies of "Actually Existing Neoliberalism". Antipode, 2002, No 3, p. 349-379. doi: https://doi.org/10.1111/1467-8330.00246

BUSTOS GALLARDO, B., LUKAS, M., STAMM, C. \& TORRE, A. (2019). Neoliberalismo y gobernanza territorial: propuestas y reflexiones a partir del caso de Chile. Revista de geografía Norte Grande, 2019, No 73, p. 161-183. doi: http://dx.doi.org/10.4067/S0718-34022019000200161

CALDEIRA, T. P. R. Peripheral urbanization: Autoconstruction, transversal logics, and politics in cities of the global south. Environment and Planning D: Society and Space, 2017, Vol. 35, N01, p. 3-20. doi: https://doi.org/10.1177/0263775816658479 
Cámara Chileno Norteamericana de Comercio AmCham. La Industria Forestal de Chile. AmCham, 01 de septiembre de 2009. Disponible en internet: https://www.amchamchile.cl/2009/09/la-industria-forestal-de-chile/

CASADO, F. Alianzas público privadas para el desarrollo. Documento de Trabajo №9. Madrid: Fundación Carolina, 2007.

CONTRERAS, Y. \& BELTRÁN, M. Reconstruir con capacidad de resiliencia: El casco histórico de la ciudad de Constitución y el sitio del desastre del terremoto y tsunami del 27 de febrero 2010. Revista INVI, 2015, No 83, p. 79-115. doi: http://dx.doi.org/10.4067/S0718-83582015000100003

DE MATTOS, C. Mercado metropolitano de trabajo y desigualdades sociales en el Gran Santiago: ¿Una ciudad dual? Revista EURE, 2002, No 85, p. 51-70. doi: http://dx.doi.org/10.4067/S025071612002008500004

DE MATTOS, C. De la planificación a la governance: implicancias para la gestión territorial y urbana. Revista Paranaense de Desenvolvimento, 2004, No 107, p. 9-23. Disponible en internet: http:// www.ipardes.gov.br/pdf/revista_PR/107/carlos_mattos.pdf

DELGADILLO, V. Urbanismo a la carta: teorías, políticas, programas y otras recetas urbanas para ciudades latinoamericanas. Cadernos Metrópole, 2014, № 31, p. 89-111. doi: https://doi. org/10.1590/2236-9996.2014-3104

DÍAZ-HORMAZÁBAL, I. \& GONZÁLEZ, M. E. Análisis espacio-temporal de incendios forestales en la región del Maule, Chile. Bosque (Valdivia), 2016, No 1, p. 47-158. doi: http://dx.doi.org/10.4067/ S0717-92002016000100014

DUCCI, M. E. (2002). Área Urbana de Santiago 1991-2000: Expansión de La Industria y La Vivienda. Revista EURE, 2002, No 85, p. 187-207. doi: http://dx.doi.org/10.4067/S0250-71612002008500010

FARÍAS, I. Devising hybrid forums. Technical democracy in a dangerous world. City, 2016, № 4, p. 549-562. doi: https://doi.org/10.1080/13604813.2016.1193998

FARÍAS, I. \& FLORES, P. A different state of exception: Governing urban reconstruction in post27F Chile. Urban Studies, 2017, No 5, p. 1108-1125. doi: https://doi.org/10.1177/0042098015620357

FUSTER, X. \& LARENAS, J. Planificación estratégica territorial y participación en contextos de desastres socio naturales: análisis del caso de Constitución post terremoto y tsunami del 27F. En Inzulza, J., Maragaño, A., Boano, C. y Díaz, I. Reconstrucción de ciudades intermedias. Procesos de gentrificación post desastres naturales. Talca: Editorial Universidad de Talca, 2018, p. 287-299.

FUSTER-FARFÁN, X. Las políticas de vivienda social en Chile en un contexto de neoliberalismo híbrido. Revista EURE, 2019, No 45, p. 5-26. doi: http://dx.doi.org/10.4067/S0250-71612019000200005

GODSCHALK, D. R. Urban Hazard Mitigation: Creating Resilient Cities. Natural Hazards Review, 2003, No 3, p. 136-143. 
GUO, Y. Urban resilience in post-disaster reconstruction: Towards a resilient development in Sichuan, China. International Journal of Disaster Risk Science, 2012, No 1, p. 45-55. doi: 10.1007 / s13753-012-0006-2

HACKWORTH, J. The Neoliberal City: Governance, Ideology, and Development in American Urbanism. New York: Cornell University Press, 2007.

HARDOY, J., PANDIELLA, G. \& VELÁSQUEZ, L. Local disaster risk reduction in Latin American urban areas. Environment and Urbanization, 2011, No 2, p. 401-413. doi: https://doi. org/10.1177/0956247811416435

HARVEY, D. The Urban Process under Capitalism: A Framework for Analysis. En Michael Dear, M. y Scott, A. J. Urbanization and Urban Planning in Capitalist Society. London: Routledge, 2018, p. 91-122.

HIDALGO, R. La vivienda social en Chile y la construcción del espacio urbano en el Santiago del siglo XX. Santiago: Ril editores, 2019.

HIDALGO, R., ALVARADO, V., VOLKER, P., ARENAS, F., \& SALAZAR, A. Ordenamiento costero metropolitano en Chile: de la expectativa de regulación a la planificación cooptada (1965-2014). Cuadernos De Vivienda Y Urbanismo, 2015, Vol. 8, N016, p. 206-225. doi https://doi.org/10.11144/ Javeriana.cvu8-16.ocmc

HIDALGO, R. \& JANOSCHKA, M. La ciudad neoliberal: Gentrificación y exclusión en Santiago de Chile, Buenos Aires, Ciudad de México y Madrid. Santiago: GEOlibros, 2014.

HIDALGO, R., BORSDORF, A., ZUNINO, H. \& ÁLVAREZ, L. Tipologías de expansión metropolitana en Santiago de Chile: precariópolis estatal y privatópolis inmobiliaria. Diez años de cambios en el Mundo, en la Geografía y en las Ciencias Sociales, 1999-2008. Actas del X Coloquio Internacional de Geocrítica, Universidad de Barcelona, 26-30 de mayo de 2008. Disponible en internet: http:// www.ub.es/geocrit/-xcol/434.htm

IMILAN, W. \& GONZÁLEZ, L. E. Attempts at Neoliberal Urban Planning in Postearthquake Chile: Master Plans for Reconstruction. Latin American Perspectives. 2017, No 4, p. 10-23. doi: https://doi. org/10.1177/0094582X16658265

INSTITUTO NACIONAL DE ESTADÍSTICAS. CENSO de población y vivienda. Santiago: INE, 2017.

INZULZA, J., MARAGAÑO, A., BOANO, C. \& DÍAZ, I. Reconstrucción de ciudades intermedias. Procesos de gentrificación post desastres naturales. Talca: Editorial Universidad de Talca, 2018.

INZULZA-CONTARDO, J. \& DÍAZ, I. Desastres naturales, destrucción creativa y gentrificación: estudio de casos comparados en Sevilla (España), Ciudad de México (México) y Talca (Chile). Revista de geografía Norte Grande, 2016, No 64, p.109-128. doi: http://dx.doi.org/10.4067/S071834022016000200008 
IRAZÁBAL, C. (dir). Learning from 27F: A Comparative Assessment Of Urban Reconstruction Processes After The 2010 Earthquake In Chile. Santiago, Columbia-Chile Fund de Columbia Global Center Santiago, CONICYT, 2015.

JIRÓN, P. \& MANSILLA, P. Las consecuencias del urbanismo fragmentador en la vida cotidiana de habitantes de la ciudad de Santiago de Chile. Revista EURE, 2014, No 121, p. 5-28. doi: http://dx.doi. org/10.4067/S0250-71612014000300001

LA SEGUNDA. Pablo Ivelic: El reconstructor del 27-F hoy lidera el repunte de Echeverría Izquierdo. Diario La Segunda. 04 de Abril de 2019.

LAWNER, M. Los arquitectos, de terremoto en terremoto. En Cares, C., Imilan, W. y Vergara, P. Reconstrucción(es) de sociedad civil: Experiencias de reconstrucción en Chile post 27F desde la sociedad civil. Santiago: Observatorio de la Reconstrucción/Heinrich Böll Stiftung Cono Sur, 2011, p. 78-84.

LEITNER, H., \& SHEPPARD, E. Provincializing Critical Urban Theory: Extending the Ecosystem of Possibilities. International Journal of Urban and Regional Research. 2016, No 1, p. 228-235. doi: https://doi.org/10.1111/1468-2427.12277

LETELIER, F. \& IRÁZABAL, C. Contesting TINA: Community Planning Alternatives for Disaster Reconstruction in Chile. Journal of Planning Education and Research. 2018 No 1, p. 67-85. doi: https:// doi.org/10.1177/0739456X16683514

LÓPEZ-MORALES, E., GASIC, IVO. \& MEZA, D. (2012). Urbanismo pro-empresarial en Chile: políticas y planificación de la producción residencial en altura en el pericentro del Gran Santiago. Revista INVI, 2012, Vol. 27, N76, p. 75-114. doi: https://dx.doi.org/10.4067/S0718-83582012000300003

LÓPEZ, E., ARRRIAGADA, C., JIRÓN, P. \& ELIASH, H. Chile Urbano Hacia El Siglo XXI. Investigaciones y Reflexiones de Politica Urbana Desde La Universidad de Chile. Santiago: Editorial Universitaria, 2013.

MARTY, F., TROSA, S. \& VOISIN, A. Les partenariats public-privé. Paris: La Découverte, 2006.

MELLA, M. Efectos sociales del terremoto en Chile y gestión política de la reconstrucción durante el gobierno de Sebastián Piñera (2010-2011). Revista Enfoques, 2012, No 16, p. 19-46. Disponible en internet: http://old.politicaygobierno.cl/wp-content/uploads/2012/07/Enfoques-16-Efectos-sociales-terremoto-Marcelo-Mella.pdf

OLAVARRÍA, M. De la formulación a la implementación del Transantiago. Análisis del proceso político de una política pública. Revista Gestión y Política Pública, 2013, № 2, p. 355-400. Disponible en internet: http://www.scielo.org.mx/scielo.php?script=sci_arttext\&pid=\$1405-10792013000200003

OLAVARRÍA, M. Conceptos básicos de política pública. Documento de Trabajo No11, 2007. Disponible en internet: http://repositorio.uchile.cl/handle/2250/123548 
ONG, A. Worlding Cities, or the Art of Being Global. En Roy, A y Ong, A. Worlding Cities: Asian Experiments and the Art of Being Global. London: Willey-Blackwell, 2011, p. 1-26.

PACTO GLOBAL. Arauco y su plan de vivienda para trabajadores obtuvo Premio Buen Ciudadano Empresarial. Pacto Global, 2015. Disponible en internet: https://pactoglobal.cl/2015/arauco-y-su-plan-de-viviendas-para-trabajadores-obtuvo-premio-buen-ciudadano-empresarial-mencion-asociativa/

PARKER, C. Tunnel-bypasses and minarets of capitalism: Amman as neoliberal assemblage. Political Geography, 2009, № 2, p. 110-120. doi: https://doi.org/10.1016/j.polgeo.2008.12.004

PELLING, M. The Vulnerability of Cities. Natural Disasters and Social Resilience. London: Earthscan, 2003.

PLISCOFF, C. \& ARAYA, J.-P. Las Alianzas Público-Privadas como gatilladoras de innovación en las Instituciones Públicas: Reflexiones a partir de la situación chilena in Revista Estado, Gobierno y Gestión Pública. Revista Estado, Gobierno y Gestión Pública, 2012, № 19, p. 173-198. doi: $10.5354 / 0717-8980.2012 .21180$

REVET, S., \& LANGUMIER, J. Le gouvernement des catastrophes. Paris: Editions Karthala, 2013.

RIVERA, C. \& WAMSLER, C. Integrating climate change adaptation, disaster risk reduction and urban planning: A review of Nicaraguan policies and regulations. International Journal of Disaster Risk Reduction, 2014, p. 78-90. doi: https://doi.org/10.1016/j.ijdrr.2013.12.008

ROBINSON, J. Thinking Cities through Elsewhere: Comparative Tactics for a More Global Urban Studies. Progress in Human Geography. 2016, No 1, p. 3-29. doi: https://doi. org/10.1177/0309132515598025

ROY, A. Urban Informality: The Production of Space and Practice of Planning. En Fainstein, S. S. y DeFilippis, J. Readings in Planning Theory. Oxford: John Wiley \& Sons, 2016, p. 524-539.

SAVAS, E. Privatization and Public-Private Partnership. En HOODGE, G. y GREEVE, C. Public-Private Partnership: An International Performance Review. Cheltenham: Edward Elgar, 2000, p. 545-558.

SEGATO, R. La crítica de la colonialidad en ocho ensayos y una antropología por demanda. Buenos Aires: Prometeo Libros, 2018.

SCHILDERMAN, T. \& LYONS, M. Resilient dwellings or resilient people? Towards people-centred reconstruction. Environmental Hazards, 2011, № 3-4, p. 218-231. doi: https://doi.org/10.1080/1747 7891.2011.598497

SILVA, P. En el nombre de la razón. Tecnócratas y política en Chile. Santiago: Ediciones Universidad Diego Portales, 2011. 
SWYNGEDOUW, E., MOULAERT, F. \& RODRIGUEZ, A. Neoliberal Urbanization in Europe: Large-Scale Urban Development Projects and the New Urban Policy. Antipode, 2002, № 3, p. 542-577. doi: https://doi.org/10.1111/1467-8330.00254

TAPIA, R. Vivienda social en Santiago de Chile. Análisis de su comportamiento locacional, período 1980- 2002. Revista INVI, 2011, No 73, p. 105-131. doi: http://dx.doi.org/10.4067/S071883582011000300004

TIRONI, M. Disastrous Publics: Counter-Enactments in Participatory Experiments. Science, Technology \& Human Values, 2014, № 4, p. 564-87. doi: https://doi.org/10.1177/0162243914560649

TURNER, J.F.C. Housing by People. Towards autonomy in building environments. London: Marion Boyards, 1976.

UGARTE, A. \& SALGADO, M. Sujetos en emergencia: acciones colectivas de resistencia y enfrentamiento del riesgo ante desastres; el caso de Chaitén, Chile. Revista INVI. 2014, No 80, p. 143-168. doi: http://dx.doi.org/10.4067/S0718-83582014000100006

UGARTE, A., SALGADO, M. \& FUSTER, X. Emergencia del sujeto político y experiencias de acción colectiva en contextos de desastres socionaturales. En: Tapia, R: y Arteaga, C. Vulnerabilidad y desastres socionaturales. Experiencias recientes en Chile. Santiago: Editorial Universitaria, 2015, p 131-148.

URETA, S. Normalizing Transantiago: On the Challenges (and Limits) of Repairing Infrastructures. Social Studies of Science. 2014, No 3, p. 368-92. doi: https://doi.org/10.1177/0306312714523855

VERGARA, P., ARAYA, J., DONOSO, S. \& FUSTER-FARFÁN, X. Reflexiones críticas sobre las Alianzas Público-Privadas (APP) como instrumentos de respuesta frente a catástrofes socio-naturales. Universitas humanística, 2016, № 82, p. 219-247. Disponible en internet: https://revistas.javeriana.edu. co/index.php/univhumanistica/article/view/13105/13263

VILLAGRA, P., HERRMANN, G., QUINTANA, C. \& SEPÚLVEDA, R. D. El pensamiento resiliente y la planificación urbana en un entorno costero bajo riesgo de tsunami: el caso de Mehuín, Chile. Revista de Geografía Norte Grande, 2016, No 64, p. 55-62. doi: http://dx.doi.org/10.4067/S071834022016000200005 